\title{
Application of automated peritoneal dialysis in urgent-start peritoneal dialysis patients during the break-in period
}

\author{
Shengmao Liu ${ }^{1} \cdot$ Xiaohua Zhuang $^{1} \cdot$ Min Zhang $^{1} \cdot$ Yanfeng Wu ${ }^{1} \cdot$ Min Liu $^{1} \cdot$ Sibo Guan $^{1} \cdot$ Shujun Liu ${ }^{1} \cdot$ Lining Miao $^{1}$. \\ Wenpeng $\mathrm{Cui}^{1}$
}

Received: 30 September 2017 / Accepted: 2 January 2018 / Published online: 16 January 2018

(c) The Author(s) 2018. This article is an open access publication

\begin{abstract}
Objective Whether automated peritoneal dialysis (APD) is a feasible strategy for urgent-start peritoneal dialysis (PD) therapy during the break-in period remains unclear. This study was conducted to compare the efficacy as well as complications among three PD modes during the break-in period.

Methods Ninety-six patients treated with urgent-start PD after catheterization were retrospectively analyzed. Patients were divided into three groups, incremental continuous ambulatory PD (CAPD) group $(n=26)$; APD group $(n=42)$; and APDCAPD group $(n=28)$. Clinical parameters at the end of the break-in period and 1 month after the initiation of PD treatment were collected and analyzed.

Results Compared with the traditional incremental CAPD, APD and APD-CAPD were superior as they could effectively remove small-molecule uremic toxins and correct electrolyte imbalance $(P<0.05)$, while did not increase the incidence of early complications during the break-in period $(P>0.05)$. However, APD led to a significant decline in albumin and pre-albumin, as compared with APD-CAPD and CAPD $(P<0.05)$. A PD strategy consisting 6 days of APD and 3 days of CAPD showed a great advantage in preventing excessive protein loss. There were no significant differences in all tested biochemical parameters among the three groups at 1 month after treatment (all $P>0.05$ ).

Conclusion Application of APD for urgent-start PD during the break-in period is feasible. A combination of APD and CAPD regimens seems to be a more reasonable mode.
\end{abstract}

Keywords Peritoneal dialysis · Break-in period · Automated peritoneal dialysis · Continuous ambulatory peritoneal dialysis

\section{Abbreviations}

APD Automatic peritoneal dialysis

CAPD Continuous ambulatory peritoneal dialysis

eGFR Estimated glomerular filtration rate

ESRD End-stage renal disease

IPD Intermittent peritoneal dialysis
Wenpeng Cui

wenpengcui@163.com

Shengmao Liu

liushengm_cc1968@sina.com

Xiaohua Zhuang

zhuangxiaohua0626@163.com

Min Zhang

1206922779@qq.com

Yanfeng Wu

156011538@qq.com

Min Liu

liuminwoniu@163.com
PD Peritoneal dialysis

RRF Residual renal function

SEM Standard error of mean
Sibo Guan

171831006@qq.com

Shujun Liu

1sjhylc@163.com

Lining Miao

miaolining55@163.com

1 Department of Nephrology, Second Hospital, Jilin University, 218 Ziqiang Street, Changchun 130041, Jilin, China 


\section{Introduction}

Peritoneal dialysis (PD) is one of the common renal replacement therapies for patients with end-stage renal disease (ESRD). The break-in period refers to the time between catheter insertion and routine catheter use. The treatment strategy used during the break-in period allows patients to adapt to the dialysis process. Patients usually undergo the PD break-in period of 2 weeks after catheterization [1]. However, there are some patients needing an urgent-start PD immediately after PD catheter insertion. In order to reduce the incidences of mechanical complications caused by urgent-start of PD treatment such as peritoneal fluid leakage and hernia, an incremental initiation of continuous ambulatory peritoneal dialysis (CAPD) is traditionally applied over the break-in period by gradual introduction of dialysate exchanges from a small-dose to full-dose therapy (e.g., from 500-800 to $2000 \mathrm{~mL}$ each session) [2]. Considering insufficient volume of dialysate exchanges, some researchers advocate intermittent PD (IPD) by increased times of dialysis fluid exchange [3]. However, frequent dialysis exchange will not only increase the workload of healthcare workers, but also incur increased risk of infection.

With the advent of automatic peritoneal dialysis (APD) machine, PD can be carried out automatically by filling and draining the dialysate, and fewer connections and disconnections could potentially reduce the risk of peritonitis [4]. In recent years, APD has been reported to be used for urgent-start PD treatment [5-7]. However, no consensus has been reached on the optimal PD mode during the break-in period, especially for the dose of PD.

In this study, a total of 96 ESRD patients who treated with urgent-start PD after catheterization were retrospectively analyzed. The aim of the study was to evaluate the different PD modes during the break-in period and to establish an appropriate treatment strategy for patients with urgent-start PD.

\section{Materials and methods}

\section{Participants}

The ESRD patients who treated with urgent-start PD after catheterization in the Second Hospital of Jilin University from October 2013 to July 2017 were enrolled. Inclusion criteria included (1) age between 18 and 85 years old, male or female; (2) diagnosis of ESRD; (3) urgent-start PD on 1-3 days after catheterization; (4) nine-day treatment during break-in period. The following criteria were used to exclude patients from this study: acute renal failure; hemodialysis during the break-in period; hemorrhagic complications after catheterization; systemic co-morbidities such as malignancies, systemic infection, cirrhosis and congestive heart failure.

\section{PD prescription}

All patients received the placement of polyester doublecuff straight Tenckhoff catheter by experienced surgeons in accordance with standard operating procedures. The implantation of PD catheter was performed by an open surgery. Briefly, a left paramedian incision was made at 9-13 cm above the pubic symphysis. Subcutaneous tissue was carefully detached to reach anterior sheath of the rectus muscle, and the anterior rectus sheath was incised $(2-4 \mathrm{~cm}$ in length). And then the posterior rectus abdominis sheath was opened and cut to expose the peritoneum after blunt detachment. The peritoneum was then incised to create a small opening. With the help of a guide wire, the PD catheter was placed into the peritoneal cavity of the abdomen. All operations were performed by the same team of clinicians.

Patients were divided into three groups according to PD prescription during the break-in period, namely APD group ( $n=42$, APD for 9 days), APD-CAPD group ( $n=28$, APD for 6 days followed by CAPD for 3 days) and CAPD group ( $n=26$, incremental CAPD for 9 days). The regimen in the APD group included 9 fill/drain cycles of $650 \mathrm{~mL}$ over $48 \mathrm{~min}$ and one long overnight dwell for the first 3 days, 8 cycles of $1000 \mathrm{~mL}$ over $48 \mathrm{~min}$ and a dwell overnight during 4-6 days, and 6 cycles of $1500 \mathrm{~mL}$ over $48 \mathrm{~min}$ and a dwell overnight during 7-9 days. The regimens in the CAPD were 4 cycles of $500-800 \mathrm{~mL}$ over $3-4 \mathrm{~h}$ and dwell overnight for the first 3 days, 4 cycles of $1000 \mathrm{~mL}$ over $3-4 \mathrm{~h}$ and dwell overnight during 4-6 days, and 4 cycles of $1500 \mathrm{~mL}$ over $4 \mathrm{~h}$ and dwell overnight during 7-9 days. Patients in the APD-CAPD group were treated with APD regimen that was consistent with the APD group for the first 6 days, and CAPD during 7-9 days (4 cycles of $1500 \mathrm{~mL}$ over $4 \mathrm{~h}$ and dwell overnight).

\section{Data collection}

The laboratory data, blood pressure, estimated glomerular filtration rate (eGFR), PD complications (PD-associated peritonitis, catheter-related infection, mechanical complications, etc.) were collected before and after the break-in period as well as at a month after the initiation of PD treatment. eGFR was calculated by CKD-EPI formula among patients who initiated PD; while for the patients who underwent PD, residual kidney GFR was estimated by the formula: (renal urea clearance rate + renal creatinine 
clearance rate)/2. A routine peritoneal equilibration test was performed at 1 month after catheterization.

\section{Statistical analysis}

The SPSS 19.0 statistical software package was used for statistical analysis. Continuous data were expressed as mean \pm standard deviation (SD), and categorical data were expressed as absolute value and percentage. Continuous data were analyzed by the $t$ test and analysis of variance with least significant difference test to evaluate differences among groups. Numeration data were analyzed with Chi-square test. $P<0.05$ was considered statistically significant.

\section{Results}

\section{Demographic and baseline characteristics of subjects}

A total of 96 ESRD patients who treated with urgentstart PD after catheterization were enrolled, including 50 (52.1\%) males and 46 (47.9\%) females, with an average age of $53.91 \pm 1.54$ (range $22-77$ ) years old. There were no significant differences in gender distribution, age, blood pressure, proportion of diabetic nephropathy, biochemical indicators, and the use of medication for hypertension control, improving anemia and decreasing phosphate levels during the break-in period among the three groups (all $P>0.05$, Table 1).

Table 1 Demographic and baseline characteristics of the subjects

\begin{tabular}{|c|c|c|c|c|}
\hline & APD group $(n=42)$ & APD-CAPD group $(n=28)$ & CAPD group $(n=26)$ & $P$ value ${ }^{\dagger}$ \\
\hline Male, $n(\%)$ & $23(54.8)$ & $14(50.0)$ & $13(50.0)$ & 0.898 \\
\hline Age (years) & $51.88 \pm 13.49$ & $55.00 \pm 16.61$ & $55.74 \pm 9.77$ & 0.527 \\
\hline Systolic blood pressure (mmHg) & $152.70 \pm 16.90$ & $147.70 \pm 18.00$ & $154.90 \pm 20.89$ & 0.418 \\
\hline Diabetic nephropathy, $n(\%)$ & $15(35.7)$ & $12(42.8)$ & $8(30.8)$ & 0.648 \\
\hline \multicolumn{5}{|l|}{ Medication, $n(\%)$} \\
\hline Antihypertensive agents & $30(71.4)$ & $22(67.9)$ & $19(73.1)$ & 0.795 \\
\hline Anemia-improving agents* & $31(73.8)$ & $22(78.6)$ & $18(69.2)$ & 0.737 \\
\hline Phosphorus-reducing agents & $22(52.4)$ & $14(50.0)$ & $15(57.7)$ & 0.845 \\
\hline Blood urea nitrogen $(\mathrm{mmol} / \mathrm{L})$ & $25.05 \pm 8.97$ & $22.66 \pm 9.12$ & $21.29 \pm 7.17$ & 0.195 \\
\hline Creatinine (umol/L) & $853.40 \pm 233.15$ & $811.10 \pm 225.99$ & $824.30 \pm 279.70$ & 0.761 \\
\hline Uric acid (umol/L) & $445.80 \pm 108.00$ & $437.70 \pm 126.78$ & $434.60 \pm 88.64$ & 0.907 \\
\hline iPTH (pg/mL) & $418.90 \pm 193.32$ & $447.90 \pm 165.40$ & $445.90 \pm 228.64$ & 0.845 \\
\hline Serum potassium $(\mathrm{mmol} / \mathrm{L})$ & $4.72 \pm 0.77$ & $4.60 \pm 0.72$ & $4.63 \pm 0.75$ & 0.803 \\
\hline Serum calcium $(\mathrm{mmol} / \mathrm{L})$ & $2.02 \pm 0.27$ & $2.08 \pm 0.23$ & $2.11 \pm 0.25$ & 0.323 \\
\hline Serum phosphorus (mmol/L) & $1.99 \pm 0.73$ & $1.89 \pm 0.59$ & $1.92 \pm 0.71$ & 0.805 \\
\hline Serum sodium $(\mathrm{mmol} / \mathrm{L})$ & $140.20 \pm 2.95$ & $140.10 \pm 3.53$ & $140.90 \pm 5.06$ & 0.735 \\
\hline $\mathrm{CO} 2-\mathrm{CP}(\mathrm{mmol} / \mathrm{L})$ & $22.24 \pm 2.39$ & $21.73 \pm 3.07$ & $22.58 \pm 3.04$ & 0.532 \\
\hline Albumin (g/L) & $35.13 \pm 6.12$ & $33.87 \pm 5.44$ & $32.93 \pm 5.52$ & 0.298 \\
\hline Pre-albumin (mg/L) & $301.20 \pm 76.53$ & $291.70 \pm 52.59$ & $289.20 \pm 75.21$ & 0.751 \\
\hline Total protein $(\mathrm{g} / \mathrm{L})$ & $65.06 \pm 11.19$ & $65.56 \pm 9.18$ & $64.15 \pm 8.71$ & 0.872 \\
\hline Fasting plasma glucose $(\mathrm{mmol} / \mathrm{L}$ & $5.61 \pm 1.55$ & $5.65 \pm 1.78$ & $5.57 \pm 1.06$ & 0.984 \\
\hline Hemoglobin (g/L) & $80.69 \pm 13.43$ & $82.54 \pm 12.46$ & $81.35 \pm 14.67$ & 0.855 \\
\hline $\mathrm{eGFR}\left(\mathrm{mL} / \mathrm{min} / 1.73 \mathrm{~m}^{2}\right)^{\#}$ & $5.71 \pm 2.10$ & $5.52 \pm 1.69$ & $6.40 \pm 2.29$ & 0.312 \\
\hline Urine volume $(\mathrm{mL})$ & $1352.00 \pm 303.57$ & $1381.00 \pm 446.44$ & $1581.00 \pm 545.54$ & 0.149 \\
\hline
\end{tabular}

APD, automatic peritoneal dialysis; CAPD, continuous ambulatory peritoneal dialysis; $\mathrm{CO} 2-\mathrm{CP}$, carbon dioxide combining power; eGFR, estimated glomerular filtration rate; iPTH, intact parathyroid hormone

*Included erythropoiesis-stimulating agents, iron, folic acid and vitamin B12

${ }^{\#}$ CKD-EPI formula was used to calculate eGFR

${ }^{\dagger}$ The $P$ values were compared among the three groups by one-way ANOVA 


\section{Comparison of changes in parameters among groups after treatment during the break-in period}

APD and APD-CAPD were able to clear small-molecule toxins (creatinine, blood urea nitrogen and uric acid) and electrolytes (potassium and phosphorus), by comparison of biochemical indicators before and after treatments $(P<0.05$, Table 2$)$. For CAPD, only clearance of blood urea nitrogen and potassium was achieved to a statistical significance level $(P<0.05)$.

We next compared the efficacy of three PD modes in the break-in period (Table 3). APD and APD-CAPD were superior to CAPD in clearance of serum creatinine, blood urea nitrogen and uric acid $(P<0.05)$. In addition, APD and APD-CAPD were more potent in reduction of potassium and phosphorus than CAPD only $(P<0.05)$. However, there was no significant difference in calcium, sodium and carbon dioxide combining power changes after treatment among groups $(P>0.05)$. APD led to a significant decline in albumin and pre-albumin, as compared with APD-CAPD and CAPD $(P<0.05)$. There was no significant difference in albumin and pre-albumin reduction between the APD-CAPD group and CAPD group $(P>0.05)$.

\section{Comparison of PD-related complications of three PD modes during the break-in period}

There were no differences in the incidences of PD-related complications among three groups, including catheter migration, PD fluid leakage, abdominal pain, abdominal distention, catheter obstruction, PD- or catheter-related peritonitis during the break-in period (all $P>0.05$, Table 4).

\section{Comparison of changes in parameters among groups at a month after treatment}

All the three types of PD models were able to clear toxins (creatinine, blood urea nitrogen, uric acid and iPTH) and improve electrolyte disorders (potassium, calcium, phosphorus and $\mathrm{CO} 2-\mathrm{CP}$ ), by comparison of biochemical indicators before and after treatment $(P<0.05$, Table 5$)$.

There were no significant differences in all tested biochemical parameters among groups at 1 month after treatment (all $P>0.05$, Table 6).

\section{Peritoneal equilibration tests for three PD modes}

There were no significant differences in the ratios of number of patients with high peritoneal transport to those with low transport among groups $(P>0.05$, Table 7$)$.

Table 2 Parameters after treatment over the break-in period

\begin{tabular}{lccccc}
\hline & APD group $(n=42)$ & $P$ & APD-CAPD group $(n=28)$ & $P$ & CAPD group $(n=26)$ \\
\hline Toxins & & & & \\
Blood urea nitrogen (mmol/L) & $14.41 \pm 5.68$ & 0.000 & $13.51 \pm 4.03$ & 0.000 & $16.40 \pm 5.43$ \\
Creatinine (umol/L) & $657.80 \pm 193.71$ & 0.000 & $627.30 \pm 154.41$ & 0.001 & $711.00 \pm 258.94$ \\
Uric acid (umol/L) & $370.60 \pm 73.48$ & 0.000 & $357.80 \pm 107.32$ & 0.014 & $404.50 \pm 87.20$ \\
Electrolytes & & & & 0.008 \\
Serum potassium (mmol/L) & $3.80 \pm 0.50$ & 0.000 & $3.75 \pm 0.51$ & 0.000 & $4.17 \pm 0.51$ \\
Serum calcium (mmol/L) & $2.12 \pm 0.25$ & 0.069 & $2.17 \pm 0.25$ & 0.154 & $2.23 \pm 0.31$ \\
Serum phosphorus (mmol/L) & $1.43 \pm 0.38$ & 0.000 & $1.27 \pm 0.27$ & 0.000 & $1.68 \pm 0.47$ \\
Serum sodium (mmol/L) & $139.00 \pm 3.75$ & 0.094 & $141.20 \pm 3.50$ & 0.277 & $141.50 \pm 3.34$ \\
CO2-CP (mmol/L) & $24.51 \pm 2.70$ & 0.000 & $24.93 \pm 3.75$ & 0.001 & $24.48 \pm 2.01$ \\
Nutritional indicators & & & & 0.132 \\
Albumin (g/L) & $29.81 \pm 4.85$ & 0.000 & $31.33 \pm 5.32$ & 0.083 & $32.32 \pm 5.38$ \\
Pre-albumin (mg/L) & $268.60 \pm 87.23$ & 0.072 & $299.60 \pm 107.41$ & 0.589 \\
Total protein (g/L) & $58.30 \pm 8.70$ & 0.003 & $61.72 \pm 8.83$ & 0.728 & $302.20 \pm 83.05$ \\
Others & & & & 0.117 & $60.19 \pm 7.18$ \\
FPG (mmol/L) & $5.32 \pm 0.87$ & 0.302 & $5.46 \pm 0.92$ & 0.691 \\
Hemoglobin (g/L) & $81.26 \pm 15.34$ & 0.856 & $83.00 \pm 11.44$ & 0.622 & $5.58 \pm 1.27$ \\
\hline APD al & & & 0.885 & $85.19 \pm 13.86$ \\
\hline
\end{tabular}

APD, automatic peritoneal dialysis; CAPD, continuous ambulatory peritoneal dialysis; $\mathrm{CO} 2-\mathrm{CP}$, carbon dioxide combining power; FPG, fasting plasma glucose. $t$ test for comparing the value before PD and after break-in period, $P<0.05$ 
Table 3 Comparison of changes in parameters after treatment over the break-in period among the three groups

\begin{tabular}{|c|c|c|c|c|c|c|}
\hline & APD group $(n=42)$ & APD-CAPD group $(n=28)$ & CAPD group $(n=26)$ & $P^{\mathrm{a}}$ & $P^{\mathrm{b}}$ & $P^{\mathrm{c}}$ \\
\hline \multicolumn{7}{|l|}{ Toxins } \\
\hline Blood urea nitrogen $(\mathrm{mmol} / \mathrm{L})$ & $-10.64 \pm 6.66$ & $-9.15 \pm 6.78$ & $-4.89 \pm 3.57$ & 0.367 & 0.000 & 0.006 \\
\hline Creatinine (umol/L) & $-195.50 \pm 114.84$ & $-183.80 \pm 161.41$ & $-113.50 \pm 61.73$ & 0.723 & 0.042 & 0.001 \\
\hline Uric acid (umol/L) & $-75.14 \pm 67.62$ & $-79.86 \pm 56.42$ & $-30.12 \pm 56.83$ & 0.762 & 0.006 & 0.002 \\
\hline \multicolumn{7}{|l|}{ Electrolytes } \\
\hline Serum potassium (mmol/L) & $-0.91 \pm 0.78$ & $-0.86 \pm 0.72$ & $-0.46 \pm 0.53$ & 0.763 & 0.012 & 0.027 \\
\hline Serum calcium $(\mathrm{mmol} / \mathrm{L})$ & $0.11 \pm 0.32$ & $0.09 \pm 0.31$ & $0.12 \pm 0.23$ & 0.879 & 0.860 & 0.743 \\
\hline Serum phosphorus (mmol/L) & $-0.57 \pm 0.61$ & $-0.61 \pm 0.63$ & $-0.24 \pm 0.38$ & 0.752 & 0.017 & 0.011 \\
\hline Serum sodium $(\mathrm{mmol} / \mathrm{L})$ & $-1.25 \pm 4.83$ & $1.03 \pm 4.63$ & $0.65 \pm 3.01$ & 0.053 & 0.078 & 0.720 \\
\hline $\mathrm{CO} 2-\mathrm{CP}(\mathrm{mmol} / \mathrm{L})$ & $2.27 \pm 2.95$ & $3.20 \pm 3.87$ & $1.91 \pm 3.92$ & 0.261 & 0.665 & 0.968 \\
\hline \multicolumn{7}{|l|}{ Nutritional indicators } \\
\hline Albumin (g/L) & $-5.30 \pm 4.70$ & $-2.54 \pm 4.37$ & $-0.60 \pm 5.12$ & 0.016 & 0.000 & 0.140 \\
\hline Pre-albumin (mg/L) & $-32.64 \pm 66.39$ & $7.89 \pm 90.43$ & $13.04 \pm 80.97$ & 0.035 & 0.014 & 0.827 \\
\hline Total protein $(\mathrm{g} / \mathrm{L})$ & $-6.76 \pm 5.78$ & $-3.87 \pm 6.66$ & $-3.96 \pm 4.98$ & 0.059 & 0.045 & 0.958 \\
\hline \multicolumn{7}{|l|}{ Others } \\
\hline FPG (mmol/L) & $-0.28 \pm 1.62$ & $-0.19 \pm 1.71$ & $0.01 \pm 1.56$ & 0.813 & 0.469 & 0.665 \\
\hline Hemoglobin $(\mathrm{g} / \mathrm{L})$ & $0.57 \pm 10.50$ & $0.46 \pm 13.03$ & $3.85 \pm 7.55$ & 0.970 & 0.172 & 0.253 \\
\hline
\end{tabular}

APD, automatic peritoneal dialysis; $\mathrm{CAPD}$, continuous ambulatory peritoneal dialysis; $\mathrm{CO} 2-\mathrm{CP}$, carbon dioxide combining power ${ }^{a}$ Comparison between the APD group and APD-CAPD group; ${ }^{b}$ comparison between the APD group and CAPD group; ${ }^{c}$ comparison between the APD-CAPD group and CAPD group

Table 4 Comparison of PD-related complications over the break-in period

\begin{tabular}{llllll}
\hline Complications, $n(\%)$ & $\begin{array}{l}\text { APD group } \\
(n=42)\end{array}$ & $\begin{array}{l}\text { APD-CAPD } \\
\text { group }(n=28)\end{array}$ & $\begin{array}{l}\text { CAPD group } \\
(n=26)\end{array}$ & Total $(n=98)$ & $P$ value \\
\hline Catheter migration & $4(9.5)$ & $3(10.7)$ & $2(7.7)$ & $9(9.2)$ & 0.929 \\
PD fluid leakage & $2(4.8)$ & $1(3.6)$ & $1(3.8)$ & $4(4.1)$ & 0.966 \\
Abdominal pain & $3(7.1)$ & $3(10.7)$ & $2(7.7)$ & $8(8.2)$ & 0.861 \\
Abdominal distention & $2(4.8)$ & $1(3.6)$ & $1(3.8)$ & $4(4.1)$ & 0.966 \\
Catheter obstruction & $1(2.4)$ & $1(3.6)$ & $1(3.8)$ & $3(3.1)$ & 0.932 \\
PD-related peritonitis & $1(2.4)$ & 0 & $1(3.8)$ & $2(2.0)$ & 0.603 \\
Catheter-related peritonitis & $1(2.4)$ & $1(3.6)$ & $2(7.7)$ & $4(4.1)$ & 0.557 \\
\hline
\end{tabular}

$\mathrm{PD}$, peritoneal dialysis

\section{Discussion}

Peritoneal dialysis is an effective method of removing of fluid and various sizes of solute molecules. Our results showed that APD and APD-CAPD were able to equivalently clear small-molecule toxins, which was superior to CAPD alone. The results were consistent with other studies [8-10]. The reasons were probably because the former was related to larger volume of dialysate exchanges, shorter retention time and more cycles. However, some researchers denied the possibility of improved clearance of small-molecule toxins by increased retention duration, which on the contrary would lead to the retention of toxic components in dialysate and decreased solute clearance rate [11]. In this study, high dose of APD yielded a superior small-molecule clearance rate, but similar intermediate- and large-molecule clearance rates in comparison with low dose of CAPD during the break-in period. These findings were similar to the previous results [10]. However, confirmation of these findings will require further investigation with a larger sample size.

Evidence has shown that the mortality rate in PD patients can be reduced by $11-47 \%$ with every increase in GFR of $5-10 \mathrm{~L} / \mathrm{min} / 1.73 \mathrm{~m}^{2}$ [12]. Preservation of residual renal function (RRF) at the greatest extent should be considered when selecting a HD mode. By observing 505 CAPD and 78 APD patients, Michels et al. [13] found that the risk of complete loss of renal function within the first years in APD group was twofold higher than that of CAPD group. The unfavorable outcome in RRF caused by 
Table 5 Parameters at a month after treatment

\begin{tabular}{|c|c|c|c|c|c|c|}
\hline & APD group $(n=42)$ & $P$ & APD-CAPD group $(n=28)$ & $P$ & CAPD group $(n=26)$ & $P$ \\
\hline \multicolumn{7}{|l|}{ Toxins } \\
\hline Blood urea nitrogen $(\mathrm{mmol} / \mathrm{L})$ & $14.07 \pm 4.76$ & 0.000 & $13.42 \pm 4.79$ & 0.001 & $11.54 \pm 3.71$ & 0.000 \\
\hline Creatinine (umol/L) & $694.40 \pm 186.75$ & 0.003 & $610.20 \pm 185.66$ & 0.004 & $638.10 \pm 211.03$ & 0.010 \\
\hline Uric acid (umol/L) & $372.00 \pm 79.12$ & 0.002 & $358.30 \pm 113.98$ & 0.045 & $382.50 \pm 82.38$ & 0.035 \\
\hline iPTH $(\mathrm{pg} / \mathrm{mL})$ & $321.20 \pm 180.91$ & 0.044 & $306.3 \pm 138.85$ & 0.014 & $305.3 \pm 159.74$ & 0.017 \\
\hline \multicolumn{7}{|l|}{ Electrolytes } \\
\hline Serum potassium $(\mathrm{mmol} / \mathrm{L})$ & $4.22 \pm 0.63$ & 0.005 & $4.15 \pm 0.46$ & 0.029 & $4.39 \pm 0.59$ & 0.210 \\
\hline Serum calcium $(\mathrm{mmol} / \mathrm{L})$ & $2.25 \pm 0.27$ & 0.000 & $2.41 \pm 0.23$ & 0.000 & $2.30 \pm 0.17$ & 0.002 \\
\hline Serum phosphorus $(\mathrm{mmol} / \mathrm{L})$ & $1.58 \pm 0.39$ & 0.006 & $1.42 \pm 0.40$ & 0.008 & $1.46 \pm 0.43$ & 0.007 \\
\hline Serum sodium $(\mathrm{mmol} / \mathrm{L})$ & $142.10 \pm 3.15$ & 0.011 & $143.70 \pm 2.77$ & 0.001 & $142.30 \pm 2.83$ & 0.209 \\
\hline $\mathrm{CO} 2-\mathrm{CP}(\mathrm{mmol} / \mathrm{L})$ & $25.37 \pm 2.68$ & 0.000 & $24.66 \pm 2.50$ & 0.002 & $25.52 \pm 3.10$ & 0.001 \\
\hline \multicolumn{7}{|l|}{ Nutritional indicators } \\
\hline Albumin $(\mathrm{g} / \mathrm{L})$ & $38.12 \pm 6.05$ & 0.042 & $38.75 \pm 3.97$ & 0.003 & $37.88 \pm 3.33$ & 0.000 \\
\hline Pre-albumin (mg/L) & $375.40 \pm 95.85$ & 0.001 & $361.80 \pm 59.67$ & 0.000 & $339.40 \pm 105.90$ & 0.056 \\
\hline Total protein $(\mathrm{g} / \mathrm{L})$ & $67.96 \pm 7.41$ & 0.213 & $70.64 \pm 7.27$ & 0.065 & $68.50 \pm 5.86$ & 0.043 \\
\hline \multicolumn{7}{|l|}{ Others } \\
\hline FPG (mmol/L) & $6.25 \pm 1.87$ & 0.111 & $7.34 \pm 3.38$ & 0.035 & $6.91 \pm 2.25$ & 0.009 \\
\hline Hemoglobin (g/L) & $107.30 \pm 15.62$ & 0.000 & $112.10 \pm 11.94$ & 0.000 & $110.20 \pm 18.98$ & 0.000 \\
\hline GFR $\left(\mathrm{mL} / \mathrm{min} / 1.73 \mathrm{~m}^{2}\right)^{\#}$ & $4.08 \pm 2.03$ & 0.003 & $4.08 \pm 1.70$ & 0.005 & $5.26 \pm 2.37$ & 0.114 \\
\hline Urine volume $(\mathrm{mL})$ & $1190.00 \pm 531.33$ & 0.153 & $1308.00 \pm 494.24$ & 0.594 & $1376.00 \pm 420.60$ & 0.181 \\
\hline
\end{tabular}

APD, automatic peritoneal dialysis; CAPD, continuous ambulatory peritoneal dialysis; $\mathrm{CO} 2-\mathrm{CP}$, carbon dioxide combining power; FPG, fasting plasma glucose; GFR, glomerular filtration rate. $t$ test for comparing the value before PD and after break-in period, $P<0.05$

\#Residual kidney GFR was estimated by the formula: (renal urea clearance rate + renal creatinine clearance rate)/2

Table 6 Comparison of changes in parameters among groups at a month after treatment

\begin{tabular}{|c|c|c|c|c|}
\hline & APD group $(n=42)$ & APD-CAPD group $(n=28)$ & CAPD group $(n=26)$ & $P$ value \\
\hline \multicolumn{5}{|l|}{ Toxins } \\
\hline Blood urea nitrogen $(\mathrm{mmol} / \mathrm{L})$ & $-10.13 \pm 7.98$ & $-8.15 \pm 10.45$ & $-8.65 \pm 7.09$ & 0.689 \\
\hline Creatinine (umol/L) & $-172.50 \pm 100.23$ & $-195.60 \pm 142.75$ & $-159.90 \pm 177.34$ & 0.731 \\
\hline Uric acid (umol/L) & $-61.77 \pm 81.87$ & $-47.13 \pm 99.23$ & $-50.84 \pm 74.94$ & 0.817 \\
\hline iPTH (pg/ml) & $-97.73 \pm 159.48$ & $-141.40 \pm 82.40$ & $-140.70 \pm 124.94$ & 0.409 \\
\hline \multicolumn{5}{|l|}{ Electrolytes } \\
\hline Serum potassium (mmol/L) & $-0.53 \pm 0.93$ & $-0.34 \pm 0.87$ & $0.01 \pm 0.65$ & 0.059 \\
\hline Serum calcium (mmol/L) & $0.26 \pm 0.24$ & $0.30 \pm 0.26$ & $0.19 \pm 0.31$ & 0.434 \\
\hline Serum phosphorus (mmol/L) & $-0.59 \pm 0.51$ & $-0.73 \pm 0.63$ & $-0.60 \pm 0.70$ & 0.728 \\
\hline Serum sodium $(\mathrm{mmol} / \mathrm{L})$ & $1.71 \pm 3.41$ & $3.30 \pm 5.14$ & $1.32 \pm 4.78$ & 0.343 \\
\hline $\mathrm{CO} 2-\mathrm{CP}(\mathrm{mmol} / \mathrm{L})$ & $2.57 \pm 3.64$ & $2.49 \pm 2.66$ & $3.12 \pm 4.50$ & 0.823 \\
\hline \multicolumn{5}{|l|}{ Nutritional indicators } \\
\hline Albumin (g/L) & $3.37 \pm 4.54$ & $4.21 \pm 4.11$ & $4.89 \pm 4.50$ & 0.443 \\
\hline Pre-albumin (mg/L) & $62.33 \pm 97.06$ & $45.44 \pm 81.62$ & $43.00 \pm 74.10$ & 0.669 \\
\hline Total protein $(\mathrm{g} / \mathrm{L})$ & $3.27 \pm 7.41$ & $6.02 \pm 4.32$ & $6.38 \pm 6.59$ & 0.169 \\
\hline \multicolumn{5}{|l|}{ Others } \\
\hline Fasting plasma glucose (mmol/L) & $0.45 \pm 2.67$ & $1.72 \pm 2.30$ & $1.42 \pm 1.77$ & 0.142 \\
\hline Hemoglobin (g/L) & $26.26 \pm 14.33$ & $32.47 \pm 14.08$ & $28.43 \pm 21.58$ & 0.475 \\
\hline GFR (mL/min/1.73 $\left.\mathrm{m}^{2}\right)$ & $-1.63 \pm 1.63$ & $-1.44 \pm 1.60$ & $-1.14 \pm 2.65$ & 0.679 \\
\hline Urine volume (mL) & $-161.70 \pm 528.45$ & $-72.92 \pm 469.64$ & $-195.50 \pm 550.74$ & 0.706 \\
\hline
\end{tabular}

$\mathrm{CO} 2-\mathrm{CP}$, carbon dioxide combining power; iPTH, intact parathyroid hormone; GFR, glomerular filtration rate

\#Residual kidney GFR was estimated by the formula: (renal urea clearance rate + renal creatinine clearance rate)/2 
Table 7 Results of peritoneal equilibration tests for three PD modes

\begin{tabular}{lllll}
\hline & APD group & $\begin{array}{l}\text { APD-CAPD } \\
\text { group }\end{array}$ & CAPD group & $P$ \\
\hline $\begin{array}{l}\text { High transport/ } \\
\text { low transport } \\
(n / n)^{\mathrm{a}}\end{array}$ & $24 / 18$ & $15 / 13$ & $15 / 11$ & 0.943 \\
\hline
\end{tabular}

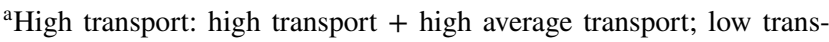
port: low transport + low average transport

APD may be explained by a large amount of ultrafiltration in a short period of time that can lead to renal ischemia. However, in a multicenter controlled study, no significant difference in RRF decline was found between APD and CAPD treatment during 90 days after the start of dialysis treatment [14]. Similarly, our results did not reveal a significant difference in GFR values among groups at 1 month after PD treatment. Efforts should be made to clarify the impact of different PD modes on the long-term RRF.

PD patients are at high risk of hypokalemia, with an incidence rate of $15-60 \%$ [15]. For a patient who undergoes a standard CAPD ( $8 \mathrm{~L} /$ day), approximate $40 \mathrm{mEq}$ of potassium ion is removed daily, and the clearance rate is about $7-26 \mathrm{~mL} / \mathrm{min}$ [16]. A study revealed increased probability of hypokalemia occurrence in patients who underwent APD at a weekly dialysis dose of $90 \mathrm{~L}$ or more [17]. In the present study, APD and APD-CAPD treatment led to more remarkable decline in potassium than CAPD did during the break-in period, probably due to short retention time and larger volume of dialysate exchanges in APD group.

A number of studies showed that the occurrence of hypokalemia and malnutrition are closely related [17-19]. Malnutrition is one of the most common complications of PD patients. According to the latest study, $67.84 \%$ of patients with PD have mild to moderate malnutrition and $7.07 \%$ have severe malnutrition [20]. A number of studies show that malnutrition is an important indicator of predicting the mortality of PD patients [21, 22]. Although APD achieves satisfactory clearance of small-molecule toxins, it leads to higher protein losses than CAPD due to multiple nighttime exchanges [8]. Our results supported the evidence that APD resulted in a more severe reduction of albumin and pre-albumin than CAPD during the break-in period. Interestingly, the levels of albumin and pre-albumin were not different among the three groups at a month after treatment. This probably is because APD enabled a potent clearance of toxins, which improved the appetite and digestive capacity of the patients, thereby promoting protein intake and absorption. Thus, APD-CAPD seemed to be an optimal PD mode during the break-in period, as it exhibited a high capacity of uremic toxin clearance and did not increase the risk of malnutrition as well.
Peritonitis is a serious complication of PD patients, leading to technical failure rate of up to $78 \%$ [23], rehospitalization rate of $13.5 \%$ [24] and PD peritonitis-related mortality rate of $15.2 \%$ [25]. The APD mode reduces the number of daily connections and disconnections and the chance of manual operation, thus decreasing the incidence of peritonitis [26]. A meta-analysis demonstrated that the incidence of peritonitis in APD group was decreased by $46 \%$ as compared with CAPD group [27]. In this study, the incidences of PD- and catheter-related peritonitis were 4.8, 3.6 and 11.5\% in the APD group, APD-CAPD group and CAPD group, respectively, suggesting the advantage of APD over CAPD as reduced incidence of peritonitis.

Patients usually undergo a PD break-in period of 2 weeks after catheterization to improve the long-term life expectancy of the catheter and minimize the mechanical complications [28]. The incidence of catheter displacement is reported as high as 12.7-35\% [29]. Immediate start of PD leads to an increased incidence of peritoneal fluid leakage (7.7\%) [7]. In this study, the overall incidence rates of catheter displacement and PD fluid leakage were 9.4\% (9/96) and $4.2 \%$ (4/96), revealing that urgent-start PD did not increase the occurrence of catheter displacement as well as peritoneal fluid leakage, which was consistent with previous study [5]. The low rates of mechanical complications in this study probably attributed to the incremental initiation of PD treatment which enabled a gradual increase in intra-abdominal pressure of patients.

This study was a single-center, retrospective cohort study with a relatively small sample size. Further studies with larger sample size are needed to confirm these findings.

In conclusion, compared with the traditional incremental CAPD, APD mode could effectively remove uremic toxins, correct electrolyte imbalance, while did not increase the incidence of early complications during the break-in period. A PD strategy consisting 6 days of APD and 3 days of CAPD showed a great advantage in preventing excessive protein loss. Thus, a combination of APD and CAPD regimens is recommend for patients with urgent-start PD during the break-in period.

Funding This study was funded by Jilin Province Science and Technology Development Program (Nos. 20150520034JH, 20150311082YY, 20160414014GH), Jilin Province Scientific Research Program (No. 2016446), Jilin Province Health and Technology Innovation Development Program (No. 2016J052) and Norman Bethune Program of Jilin University (No. 2015214).

\section{Compliance with ethical standards}

Conflict of interest All the authors declare that they have no conflict of interest.

Ethical approval All procedures performed in studies involving human participants were in accordance with the ethical standards of the insti- 
tutional and/or national research committee and with the 1964 Helsinki declaration and its later amendments or comparable ethical standards.

Informed consent Informed consent was obtained from all individual participants included in the study.

Open Access This article is distributed under the terms of the Creative Commons Attribution 4.0 International License (http://creativecomm ons.org/licenses/by/4.0/), which permits unrestricted use, distribution, and reproduction in any medium, provided you give appropriate credit to the original author(s) and the source, provide a link to the Creative Commons license, and indicate if changes were made.

\section{References}

1. Figueiredo A, Goh BL, Jenkins S, Johnson DW, Mactier R, Ramalakshmi S, Shrestha B, Struijk D, Wilkie M, International Society for Peritoneal D (2010) Clinical practice guidelines for peritoneal access. Perit Dial Int J Int Soc Perit Dial 30(4):424-429. https://doi.org/10.3747/pdi.2010.00087

2. Liu Y, Zhang L, Lin A, Ni Z, Qian J, Fang W (2014) Impact of break-in period on the short-term outcomes of patients started on peritoneal dialysis. Perit Dial Int J Int Soc Perit Dial 34(1):49-56. https://doi.org/10.3747/pdi.2012.00293

3. Wang C, Fu X, Yang Y, Deng J, Zhang HQ, Deng HM, Lu J, Peng Y, Liu H, Liu FY, Liu Y (2017) A comparison between intermittent peritoneal dialysis and automatic peritoneal dialysis on urgent peritoneal dialysis. Am J Nephrol 45(6):540-548. https://doi. org/10.1159/000477178

4. Ronco C, Amerling R, Dell'aquila R, Rodighiero MP, Di Loreto P (2006) Evolution of technology for automated peritoneal dialysis. Contrib Nephrol 150:291-309. https://doi.org/10.1159/000093624

5. Jo YI, Shin SK, Lee JH, Song JO, Park JH (2007) Immediate initiation of CAPD following percutaneous catheter placement without break-in procedure. Perit Dial Int J Int Soc Perit Dial 27(2):179-183

6. Stegmayr BG (2003) Three purse-string sutures allow immediate start of peritoneal dialysis with a low incidence of leakage. Semin Dial 16(4):346-348

7. Povlsen JV, Ivarsen P (2006) How to start the late referred ESRD patient urgently on chronic APD. Nephrol Dial Transplant 21(Suppl 2):ii56-ii59. https://doi.org/10.1093/ndt/gfl192

8. Westra WM, Kopple JD, Krediet RT, Appell M, Mehrotra R (2007) Dietary protein requirements and dialysate protein losses in chronic peritoneal dialysis patients. Perit Dial Int J Int Soc Perit Dial 27(2):192-195

9. Pham NM, Recht NS, Hostetter TH, Meyer TW (2008) Removal of the protein-bound solutes indican and p-cresol sulfate by peritoneal dialysis. Clin J Am Soc Nephrol CJASN 3(1):85-90. https://doi. org/10.2215/CJN.02570607

10. Bammens B, Evenepoel P, Verbeke K, Vanrenterghem Y (2005) Time profiles of peritoneal and renal clearances of different uremic solutes in incident peritoneal dialysis patients. Am J Kidney Dis 46(3):512-519. https://doi.org/10.1053/j.ajkd.2005.05.016

11. Eloot S, Vanholder R, Dequidt C, Van Biesen W (2015) Removal of different classes of uremic toxins in APD vs CAPD: a randomized cross-over study. Perit Dial Int J Int Soc Perit Dial 35(4):436-442. https://doi.org/10.3747/pdi.2013.00202

12. Wang AY, Lai KN (2006) The importance of residual renal function in dialysis patients. Kidney Int 69(10):1726-1732. https://doi. org/10.1038/sj.ki.5000382

13. Michels WM, Verduijn M, Grootendorst DC, le Cessie S, Boeschoten EW, Dekker FW, Krediet RT, Group NS (2011) Decline in residual renal function in automated compared with continuous ambulatory peritoneal dialysis. Clin J Am Soc Nephrol CJASN 6(3):537-542. https://doi.org/10.2215/CJN.00470110

14. Cnossen TT, Usvyat L, Kotanko P, van der Sande FM, Kooman JP, Carter M, Leunissen KM, Levin NW (2011) Comparison of outcomes on continuous ambulatory peritoneal dialysis versus automated peritoneal dialysis: results from a USA database. Perit Dial Int J Int Soc Perit Dial 31(6):679-684. https://doi.org/10.3747/pdi.2010 .00004

15. Yongsiri S, Thammakumpee J, Prongnamchai S, Tengpraettanakorn P, Chueansuwan R, Tangjaturonrasme S, Dinchuthai P (2015) Randomized, double-blind, placebo-controlled trial of spironolactone for hypokalemia in continuous ambulatory peritoneal dialysis patients. Ther Apheresis Dial 19(1):81-86. https://doi.org/10.1111/1744 $-9987.12219$

16. Zanger R (2010) Hyponatremia and hypokalemia in patients on peritoneal dialysis. Semin Dial 23(6):575-580. https://doi.org/10.1111 /j.1525-139X.2010.00789.x

17. Szeto CC, Chow KM, Kwan BC, Leung CB, Chung KY, Law MC, Li PK (2005) Hypokalemia in Chinese peritoneal dialysis patients: prevalence and prognostic implication. Am J Kidney Dis 46(1):128-135

18. Chuang YW, Shu KH, Yu TM, Cheng CH, Chen CH (2009) Hypokalaemia: an independent risk factor of Enterobacteriaceae peritonitis in CAPD patients. Nephrol Dial Transplant 24(5):16031608. https://doi.org/10.1093/ndt/gfn709

19. Jung JY, Chang JH, Lee HH, Chung W, Kim S (2009) De novo hypokalemia in incident peritoneal dialysis patients: a 1-year observational study. Electrolyte Blood Press E BP 7(2):73-78. https://doi. org/10.5049/EBP.2009.7.2.73

20. Prasad N, Sinha A, Gupta A, Bhadauria D, Manjunath R, Kaul A, Sharma RK (2016) Validity of nutrition risk index as a malnutrition screening tool compared with subjective global assessment in endstage renal disease patients on peritoneal dialysis. Indian J Nephrol 26(1):27-32. https://doi.org/10.4103/0971-4065.158449

21. Malgorzewicz S, Chmielewski M, Kaczkan M, Borek P, Lichodziejewska-Niemierko M, Rutkowski B (2016) Nutritional predictors of mortality in prevalent peritoneal dialysis patients. Acta Biochim Polonica 63(1):111-115. https://doi.org/10.18388/abp.2015_1070

22. Leinig CE, Moraes T, Ribeiro S, Riella MC, Olandoski M, Martins C, Pecoits-Filho R (2011) Predictive value of malnutrition markers for mortality in peritoneal dialysis patients. J Ren Nutr 21(2):176183. https://doi.org/10.1053/j.jrn.2010.06.026

23. Woodrow G, Turney JH, Brownjohn AM (1997) Technique failure in peritoneal dialysis and its impact on patient survival. Perit Dial Int J Int Soc Perit Dial 17(4):360-364

24. Fried L, Abidi S, Bernardini J, Johnston JR, Piraino B (1999) Hospitalization in peritoneal dialysis patients. Am J Kidney Dis 33(5):927-933

25. Perez Fontan M, Rodriguez-Carmona A, Garcia-Naveiro R, Rosales M, Villaverde P, Valdes F (2005) Peritonitis-related mortality in patients undergoing chronic peritoneal dialysis. Perit Dial Int J Int Soc Perit Dial 25(3):274-284

26. Bieber SD, Burkart J, Golper TA, Teitelbaum I, Mehrotra R (2014) Comparative outcomes between continuous ambulatory and automated peritoneal dialysis: a narrative review. Am J Kidney Dis 63(6):1027-1037. https://doi.org/10.1053/j.ajkd.2013.11.025

27. Rabindranath KS, Adams J, Ali TZ, Daly C, Vale L, Macleod AM (2007) Automated vs continuous ambulatory peritoneal dialysis: a systematic review of randomized controlled trials. Nephrol Dial Transplant 22(10):2991-2998. https://doi.org/10.1093/ndt/gfm515

28. Dombros N, Dratwa M, Feriani M, Gokal R, Heimburger O, Krediet R, Plum J, Rodrigues A, Selgas R, Struijk D, Verger C, Dialysis EEGoP (2005) European best practice guidelines for peritoneal dialysis. 3 Peritoneal access. Nephrol Dial Transplant 20(Suppl 9):ix8-ix12. https://doi.org/10.1093/ndt/gfi1117 
29. Radhakrishna K, Sandeep P, Chakarpani U, Venkata Rami Reddy V, Ram R, Siva Kumar V (2014) Insertion technique for prevention of peritoneal dialysis catheter tip migration. Int Urol Nephrol 46(9):1867-1868. https://doi.org/10.1007/s11255-014-0727-9 